\title{
'Selfie Journalism’: Current Practices in Digital Media
}

\author{
Maniou, A. Theodora ${ }^{1}$, Veglis, Andreas ${ }^{2}$ \\ ${ }^{1}$ Department of Journalism, Frederick University, Cyprus. \\ ${ }^{2}$ School of Journalism and Mass Communication, Aristotle University of Thessaloniki, Greece. \\ Correspondence: Maniou, A. Theodora, Department of Journalism, Frederick University, Nicosia, 7, Y. Frederickou str, \\ 1036, Cyprus.
}

Received: May 3, 2016 Accepted: May 19, 2016 Online Published: May 27, 2016

doi:10.11114/smc.v4i1.1637

URL: http://dx.doi.org/10.11114/smc.v4i1.1637

\begin{abstract}
In a world of technological convergence, the fast growing tendency for self-exposure through the digital media and social networks has been steadily gaining ground as a new field for academic study. The so-called 'selfie' photographs, one of the most noteworthy phenomena of our era, seem to be altering not only the way individuals interrelate through digital platforms but also the way (s) digital journalism practices are exercised. This article examines the ways 'selfies' are embedded in everyday journalism practice and the specific issues that arise from this practice. In this perspective, this article introduces the term 'selfie journalism' and attempts to investigate the transformation of journalism practice through the use of personal digital devices.
\end{abstract}

Keywords: selfie, digital media, journalism, social networks

\section{Introduction}

In a world that changes everyday that goes by, not only younger but also older users have been enthusiastic over the past few years about embracing new networking tools and now rely on social/digital network platforms to help maintain contact with friends, families and colleagues, and manage their daily communications - sharing links, photos, videos, news and status updates (Ciboh, 2015). The rapidly growing tendency for self-exposure/self-representation through the Digital Media has gained ground in recent years as a field for academic study, not only in the area of Cultural Studies but also in the Visual Studies sector. This article suggests that there is a growing need to further explore this phenomenon in the field of Journalism and Media Studies and its principal purpose is to outline a framework from the newly arisen practice of 'selfie journalism', deriving from the embedment of 'selfies' in everyday journalistic practices.

The so called 'selfie' photographs constitute one of the most notable phenomena within the current digital media environment, linking their remarkable outspread and popularity to the use of smart digital devices (phones, tablets, etc.). As a result, it was only a matter of time for selfies to be incorporated in the current journalistic practices, raising - at the same time - a number of issues, relating to notions of subjectivity, infotainment and private sphere. This article examines the role of 'selfies' in the current journalistic practices in the digital media. Starting from their history and their role in the popular political and social culture, the article analyses specific issues, relating to their incorporation in the everyday journalistic practices and the way(s) selfies transform contemporary journalism.

\section{Literature Review}

\subsection{The Technological Evolution of Self-representation}

While self - exposure is rapidly evolving as the key element of social media practices, the projection of personal images is not a new phenomenon, since its popularity can be related to other trends dating back to the last decades of the twentieth century, such as the rise of artists and photographers who focused their work mostly on self- portraiture (Busseta \& Coladonato, 2015). The mode of selfies has come a long way from days of Vincent van Gough, who first painted a self portrait to the days of Triple self portrait painted by Norman Rockwell, which features a mirror selfie (Saravanan \& Nithyaprakash, 2015). As Ibrahim (2015) argues, from paintings, sculptures, photographs to tombstones, we turn to cultural artefacts to imprint our mortal existence and to elongate it after death. Undoubtedly, there is a venerable history of photographic self-portraiture (Lingwood, 1986), although literally putting oneself in the picture (Spence, 1986) in the past relied on technological work-arounds like timers or remote-control devices, the use of reflective surfaces or a human proxy (see also Frosh, 2015). 
Today, there is a variety of technological gadgets that allow us to surpass such difficulties and, at the same time, abridge any possible drawback; for example, unlike film-based photography which had associated costs with film processing, digital photography has an ease of exchange and storage (Ibrahim, 2015), while technology convergence and the digitisation of images allows the embedment of self-representation in everyday life. The most widely used devices that support selfie photographs are smartphones and tablets.

A smartphone is a high-end mobile phone that combines the functions of a personal digital assistant and a mobile phone, while supporting features like portable media player and camera with high-resolution touch screen, GPS navigation, Wi-Fi and mobile broadband access (Ajay \& Jayanth, 2014; Veglis, 2012). Tablets are portable PCs that include touch screens and wireless connection to the Internet. These devices offer relatively large high resolution displays and an extensive storage capacity (in comparison with other mobile devices, for example smartphones) (Wearden and Fidler, 2001). The majority of smartphones and tablets include two cameras (front face and back face) (Fiebig, Krissler, \& Hänsch, 2014). Although the front face camera is usually of lower resolution, it is considered to be adequate for selfie photographs. While smartphones include cameras with advanced features, this particular accessory has not been exploited to its full potential (Koukoumidis, Martonosi, \& Peh, 2012). This seems to have changed to some degree with the introduction of the selfie photograph trend but also of other medical uses.

It is also worth noting that the worldwide smartphone market grew 13.0\% year over year in 2015 Q2, with 341.5 million shipments (IDC, 2015) and today it is estimated that there are 2.6 billion smartphone subscriptions globally. By 2020, it is believed that globally there will be 6.1 smartphone users (70\% of the world population) (Lunden, 2015).

\subsection{Defining 'Selfies'}

The selfie is part of the broader social process of home mode communication (Chalfen, 1987). If perceived as an amateur's act, it can largely contribute to the global circulation of personal images and data; however, seen as a professional practice, it is undoubtedly a photographic object that initiates the transmission of feelings within the establishment of a relationship among viewers and viewed, images and filtering software (Senft \& Baul, 2015). A selfie is also a practice - a gesture that can send different messages to different individuals, communities and audiences; this gesture may be dampened, amplified or modified by the media (Gupta \& Pooza, 2016). While the easy explanation is that selfies exist as emblems of a narcissistic contemporary culture, a deeper reading of selfies instead provides insight into the relationships between technology, the self, materiality, and networks (Hess, 2015).

In this work, our definition of 'selfies' is mainly based on the work of Farci and Orefice (2015) that describe selfies as ' those personal snapshots that: (a) are created with the awareness of belonging to a specific genre of self-portraits; $(b)$ combine textual and iconic dimensions; and (c) are distributed in one's own social network'.

In this perspective, selfies in the digital media environment are directly linked to issues of identity online. As Leary (2013) argues selfies are used to express a specific notion of the self, particularly the one that people think will garner social rewards. Recent research shows that selfies represent one's identity through different contexts, such as different physical spaces and/or personal frames (see Drenten, 2012; Mendelson \& Papacharissi, 2011).Most of these works begin from the notion of Goffman's approach (1959), in which he argues that people strive for ideal social role presentations in relation to a specific context and situation, which have to meet the social expectations of others in order to be seen as authentic. As such, selfies create context-bound identities that verify the existence of this presented identity in relation to a specific time and space and can also be understood as a sign of proof that underlines the activity of witnessing an event by placing oneself in a particular space and time (Koliska \& Roberts, 2015). To this perspective then, the process of taking and sharing a selfie can lead to a constructed identity based on the object's desire to be seen as such by the others rather than a genuine one.

\section{Selfie Journalism}

What makes selfies become the new 'journalistic tools' in the digital media environment is the practice of sharing and, thus, distributing to a global audience highly personalized 'stories'/moments/events, following the widely growing tendency for people to broadcast themselves. Social media preserve a principal role in this procedure, since, as Highfield (2016) argues, from selfies and memes to hashtags and parodies, social media are used

for mundane and personal expressions of commentary, engagement, and participation. The pillars of social self-understanding and self-presentation today are in the midst of a reconstruction process: What constitutes public spheres, what produces and disseminates representations and what defines a journalist against the backdrop of the incessant spread of rapid digital media changes; these transformation processes impact practically on all aspects of the communicative construction of social reality (Kramp, Carpentier \& Hepp, 2015) .

In 2013, President Obama, Danish Prime Minister, H. Thorning-Schmidt and British Prime Minister, D. Cameron decided to take a selfie in Mandela's funeral; once shared in the digital and social media, the depiction of the selfie 
itself became the 'news' instead of their presence to the funeral, raising issues of appropriateness and ethics. As photojournalist Roberto Schmidt, who was behind the camera, says 'this photo suggests a sign of our times that somehow this image seemed to get more attention than the event itself' ${ }^{\prime}$.

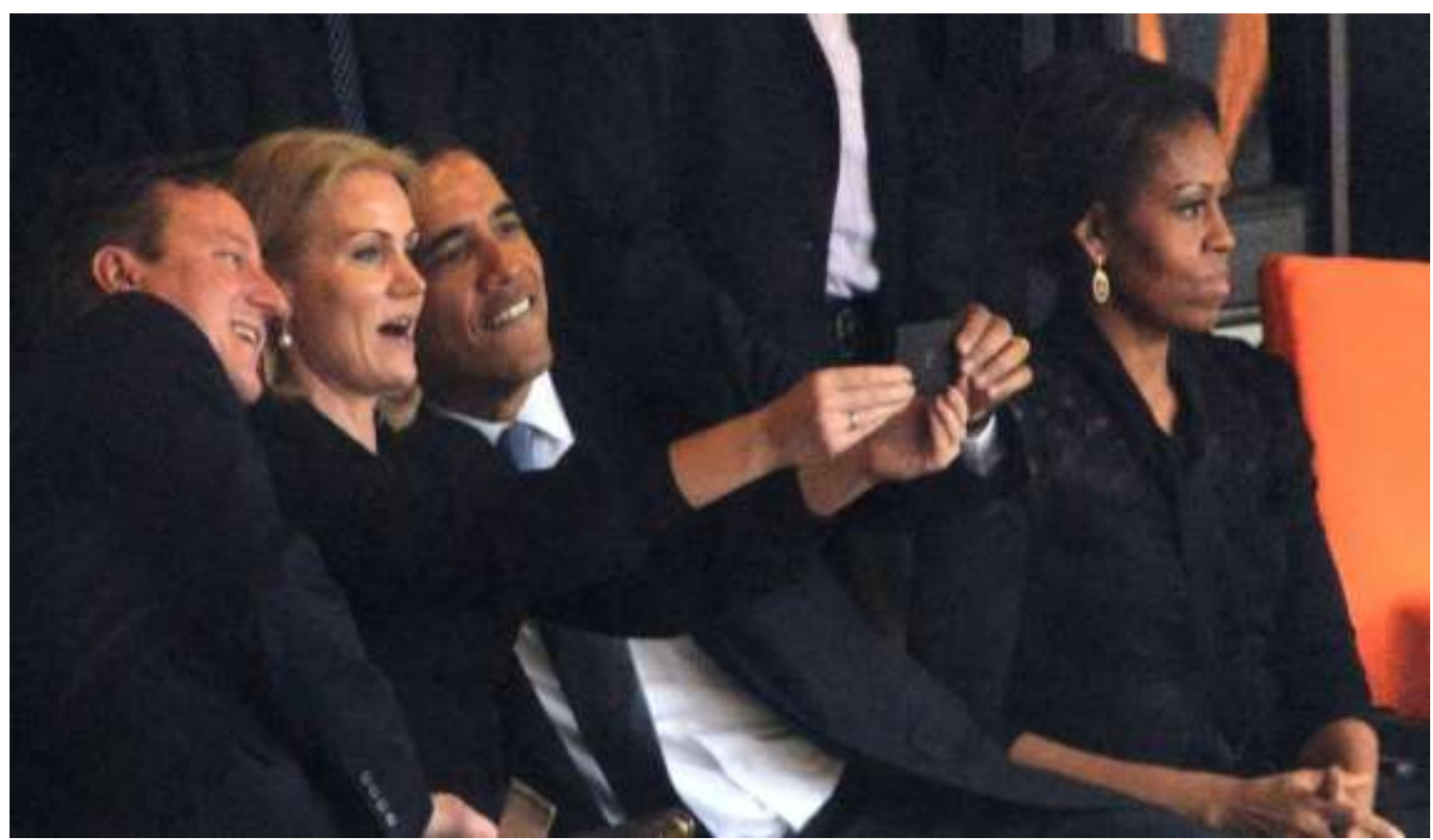

Picture 1. Obama, Schmidt and Cameron's depiction of selfie at Mandela's funeral

Historically, witnessing tokens play a paramount role in the news stories. Selfies can be seen as not only the most evident tokens of witnessing an event but also as the way the individual perceives this event. As Koliska \& Roberts (2015) argue selfies first 'see' or capture a moment of an event and then 'say' something about it when the image is shared with others. In this respect, selfies are analogous to the communication situation of broadcasting, which displays reporters in various locations and where 'experiences are mediated to an audience which has no first-hand acquaintance with them' (see also Peters, 2001; Maniou \& Eteokleous-Grigoriou, 2014). However, in a networked world, as Kumar (2012) explains, media events are on a feedback-loop of relentless course correction in response to what is being reported, and, as each participant is also a veritable node in the media network, no event can unfold in isolation from its witnessing.

In fact, it is not the selfie itself that changes the current journalistic practices, but the technology evolved around it. Smart technology, deployed through personal portable devices - such as, smartphones and tablets, has eliminated issues of time in the process of sharing and globally distributing witnessing tokens. Today, HD cameras incorporated in this infrastructure allow the up-to-the-minute disclosure of witnessing tokens, deescalating most of the times the reportage itself: once shared a video or a photograph, there is no need for instant description, since a title (usually in the form of a hashtag) is simply enough. In this perspective, the reportage is the photograph, while the journalistic analysis and interpretation follows and does not precede the story.

It is not new that the integration of social media into journalistic practices has been ongoing for many years (O'Donnellet al, 2013). As Chen (2013) argues, this is partly due to generational change, personal branding, market sensing, and new forms of elite interaction performed in public. However, in the early years, journalists tended to be more selective concerning the material they imported from the social media into their news stories (Chen, 2013). But as technology evolves and alternative modes of digital story-telling arise, this newly formed digital public sphere tends to overwhelm the agenda setting process of the media, bringing forward issues, events and/or individual people previously highlighted by the social media. The rapid rise of Instagram-or more recently Vine - is the solid proof for this argument: politicians, actors, singers and various 'social personas' emerge and prevail the current public sphere solely based on their selfie portraits in the digital world, enabling them to geo-tag their locations when they broadcast their content.

\footnotetext{
${ }^{1}$ See analysis at http://www.forbes.com/sites/tamlinmagee/2013/12/30/what-obamas-mandela-funeral-selfie-tells-us-about-the-web-in-2 014/\#311341a81495
} 
Even the 'paparazzi' techniques today seem meaningless, since the so-called famous people choose to publicize their most private moments by themselves, using the most popular digital networks. In this perspective, engagement is now the key and Selfie Journalism constitutes the new trend bringing Mobile Journalism a step forward: counting how many Facebook likes our stories get or tallying YouTube views for a video, is yesterday's social media strategy. Today we want to know how people are commenting, starting conversations, and more importantly, how are they sharing journalistic content (Omar, 2015).

Additionally, journalists today instead of presenting the news seem to be the news, as they deploy tactics of self-representation while in the process of searching for news. Selfies depicting journalists with their interviewees, while reporting on site -even in war or terrorism situations - seem to be among the most shared content in the digital world, much more than the news content itself. In March 2016, in an alleged terrorist take over of an Egyptian airplane in the airport of Larnaca, Cyprus, one of the passengers publicized in his social media profile a selfie with the alleged terrorist ${ }^{2}$. The selfie was instantly shared and reproduced by the global media, bringing forward a notion of infotainment to the news story.

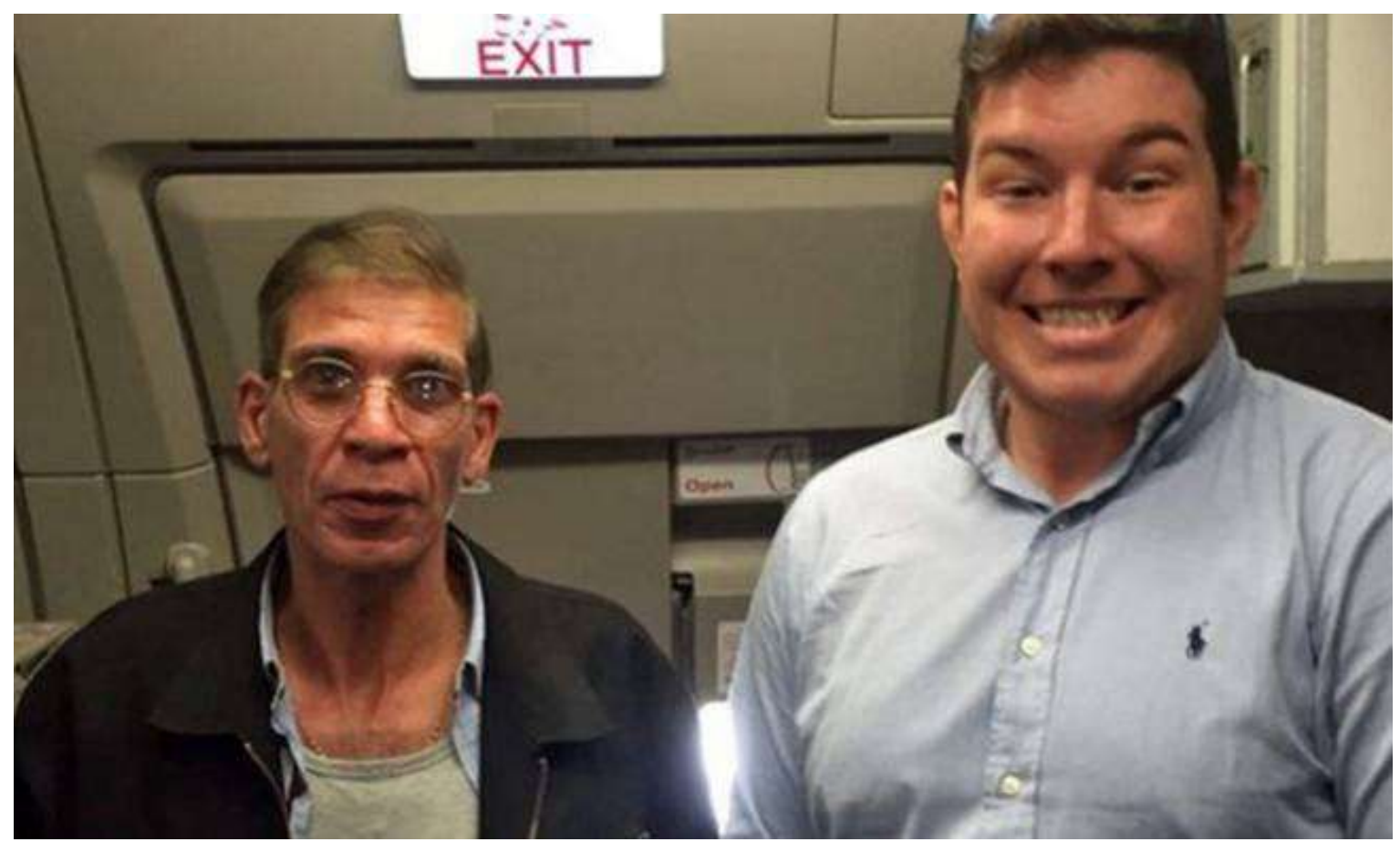

Picture 2. Selfie with the alleged terrorist in an airplane take over in Cyprus.

In this perspective, there is a huge issue concerning the content itself of selfie journalism. Selfies' main value tends to be more emotional than aesthetic, since they are based on rather amateur than professional techniques (see analysis at Tifentale \& Manovich, 2015). In any case, selfies used to reproduce journalistic content do not depict isolated objects, but they are proven records of events, since they include background information and/or items/activities/other people/gestures framing the 'author' of the photograph. In this way, it is this exact 'framing' that becomes today's news putting the author into the story; for example, by pinpointing an object or a piece of the background scenery, the author automatically draws attention to it, placing this object in the centre of the viewers' interest and, thus, brings the frame forward as the main issue of the news story. For example, Le Monde reporter Thomas Wieder was so proud to be reporting from the White House that he posted the following picture of himself to Twitter for the world to see.

\footnotetext{
2 As proved, the alleged terrorist in fact took over the airplane in order to attract media attention for personal reasons regarding his ex-wife and children. The incident was terminated within a few hours by the local authorities.
} 


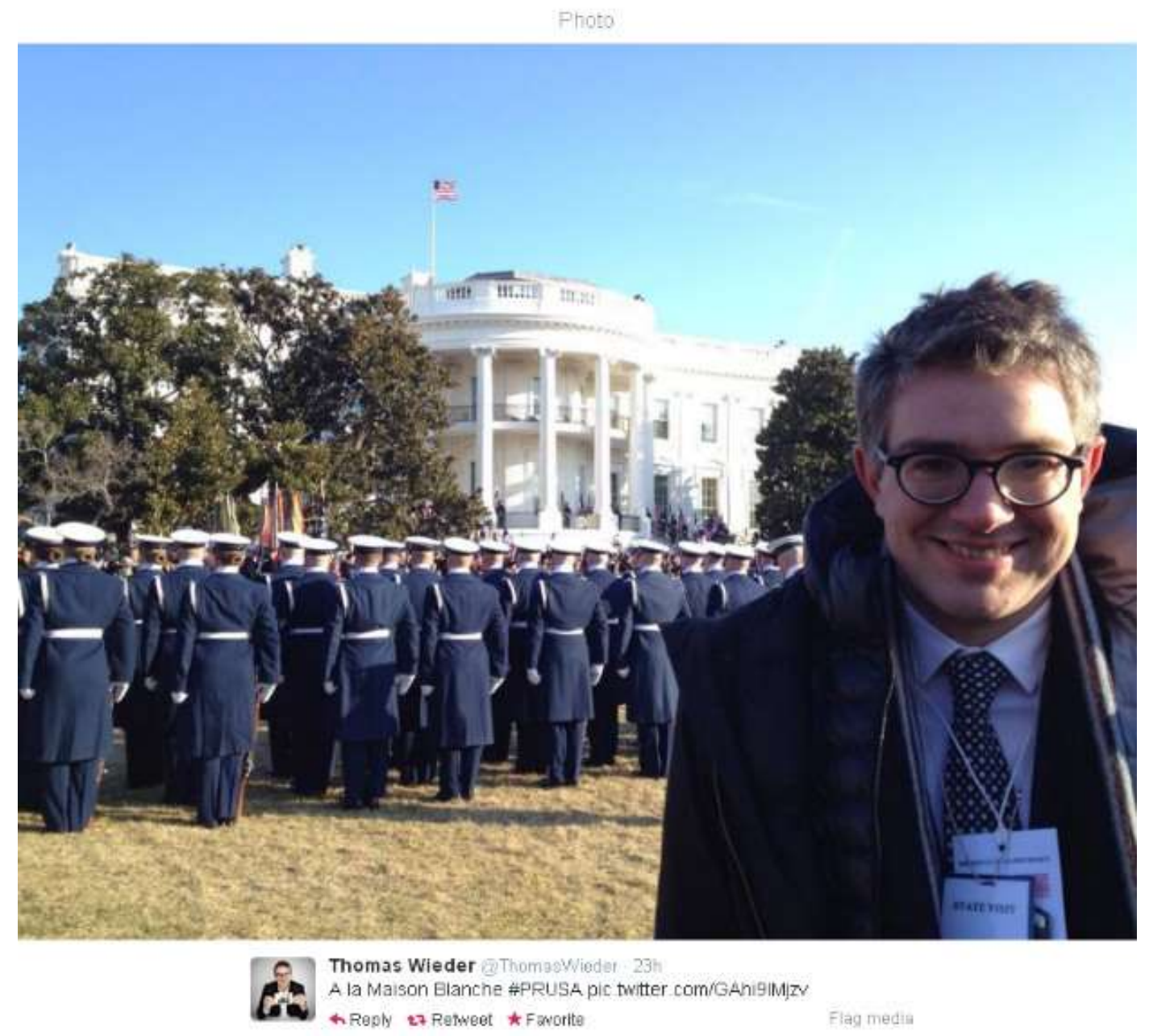

Picture 3. Le Monde reporter Th. Wieder is taking a selfie outside the White House.

\section{Issues of Pathogenicity}

The first and foremost issue that arises for selfie journalism is linked to the realm of copyright. By now, the average user of digital and social media worldwide is well aware of the fact that digital platforms' standard terms of use offers to the company owners the license to reclaim all posts uploaded and shared online. It is not in the immediate goals of this paper to examine why then users continue to exercise such practices. However, the question that arises is what happens in the case of copyright issues concerning authentic journalistic content. Under a straightforward reading of such legal cases in recent years in the USA, the selfie merits copyright protection with little debate: the author has clearly put mental effort into the 'composition' of the scene by choosing an outfit, finding the right angle, and picking a particular expression for his/her face (Storella, 2015). But, once uploaded and shared, a selfie becomes accessible by hundreds of thousands of users as well as by the digital platform it self. In this perspective, anyone can use it as he/she pleases.

Another core issue that selfie journalism raises is the amount of personal information we can release and share. Digital platforms offer a variety of categorized or uncategorized personal data that can be analyzed algorithmically, creating in this way a digital profile for each individual. Several scholars have already emphasized their limited faith in seeing this adaption within news organizations in the nearby future (Oie, 2015) and most of them are concerned with privacy issues around media use of personal data (Goggin, Martin \& Dwyer, 2014). As Gomez-Cruz and Thornham (2015) argue the issue here is how the combination of visual, material and digital elements of selfies create new forms of surveillance and 'sousveillance', reshape what privacy, public and intimacy are and can, in this perspective, generate softer and more effective forms of power.

At the same time, this type of journalism seems to be affecting the way history is now documented, embedding elements of direct infotainment characteristics in matters of political and social life; in fact, the smart element of all portable devices refers to its ability to be 
reconfigured and repurposed by users through their choice of downloadable apps (Watkins, Hjorth \& Koskinen, 2012), that can edit and re-shape content (i.e., edit a photograph, amend possible undesired elements, etc.). To this perspective, are the events of timeliness documented via selfie journalism as they are happening or as we want to see and interpret them? If the latter is the case, can selfie journalism be trustworthy?

\section{Conclusion and Future Research}

This paper attempts to highlight a new phenomenon in the contemporary media practices that emerged from the growing tendency to post and share selfie photographs via digital platforms. Following the rapid proliferation of selfies, it was only a matter of time for them to be incorporated in the journalistic practice and adhere to the rise of a new tendency in journalism - the so called 'selfie journalism'.

The principal characteristics of this newly introduced tendency include, but are not limited to, the reconstruction of public sphere and contemporary reality, the interest relocation from the event to the image, the up-to-the-minute disclosure and sharing of witnessing tokens with a global audience and the participation of journalists themselves in the stories they are covering. All these characteristics can lead to the surpass of past practices, such as 'paparazzi' tactics since now celebrities of every kind tend to reveal their personal stories via selfies in the digital media, while infotainment tends to evolve in a new level of mediatised communication: by sharing the story, the 'object' itself manages to co-create this story based on the specific element(s) he/she chooses to draw attention to.

However, as analysed above, selfie journalism brought forward issues of pathogenicity, such as copyright claims, the amount of private information released to a global audience as well as issues of credibility and validity, since this newly formed genre of journalism seems to be affecting the way history is now documented.

Undoubtedly, there are several important aspects in the area of 'selfie journalism' that require further research. For instance, the socio-economic aspects of such a practice and the qualitative alteration of the news content; on the one hand, 'selfie journalism' includes the element of citizen journalism in terms of amateur practices of sharing witnessing tokens and, as such, may pose a real threat to professional journalism. On the other hand, news content seems to be altering in order to meet the demands of selfie journalism: hashtags, memes and key words may result to the diminishing of content and the substitution of word-based reporting with image-centred stories available to subjective interpretation. A future extension of this work will include the qualitative study of these two aspects of selfie journalism, in order to clarify the relation between them: socio-economic consequences in professional journalism and alteration of the news content. One may argue that it is the technology that is supposed to enhance the upgrading of the content and not the other way around. It remains to be seen whether this will be the case in the years to follow...

\section{References}

Ajay, Y., \& Jayanth, J. (2014). Rating of Smart Phone Features - A Demographic Study. Global Journal of Emerging Trends in e-Business, Marketing and Consumer Psychology (GJETeMCP), 1, 30- 40.

Busetta, L., \& Coladonato, V. (2015). 'Introduction - Be your Selfie: Identity, Aesthetics and Power in Digital Self-representation'. Networking Knowledge, 8(6), 1-3.

Chalfen, R. M. (1987). Snapshot Versions of Life. Bowling Green Ohio: Bowling Green State University Popular Press.

Chen, P. J. (2013). 'New Media in the Electoral Context: The new normal'. In C.

Ciboh, R. (2015). 'Adult Users' Engagement and Utilisation of Social Networks Sites in Nigeria'. Studies in Media and Communication, 3(2), 129 - 136. http://dx.doi.org/10.11114/smc.v3i2.1169

Drenten, J. (2012). 'Snapshots of the self'. In A. Close (ed.), Online consumer behaviour:Theory and research in social media, advertising and e-tail (pp.3-34). New York, NY: Routledge.

Farci, M., \& Orefice, M. (2015). 'Hybrid Content Analysis of the Most Popular Politicians'Selfies on Twitter'. Networking Knowledge, 8(6). Retrieved at 12 April 2016 at http://www.ojs.meccsa.org.uk/index.php/netknow/article/view/401/230

Fiebig, T., Krissler, J., \& Hänsch, R. (2014). 'Security Impact of High Resolution Smartphone Cameras. 8th Usenix Workshop on Offensive Technologies'. Available at https://www.usenix.org/system/files/conference/woot14/woot14-fiebig.pdf

Frosh, P. (2015). 'The Gestural Image: The Selfie, Photography Theory and Kinaesthetic Sociability'. International Journal of Communication, 9(1), 607-1628.

Goffman, E. (1959). The presentation of self in everyday life. Garden City, NY: Doubleday.

Goggin, G., Martin, F., \& Dwyer, T. (2014). 'Locative News'. Journalism Studies, 1-19. http://dx.doi.org/10.1080/1461670X.2014.890329 
Gomez-Cruz, E., \& Thornham, H. (2015). 'Selfies beyond Self-Representation: The (theoretical) f(r)ictions of a practice'. Journal of Aesthetics \& Culture, 7. http://dx.doi.org/10.3402/jac.v7.28073

Gupta, R., \& Pooza, M. (2016). 'Selfie: An Infectious Gift of IT to Modern Society'. Global Journal of Research Analysis, 5(1), 278-280.

Hess, A. (2015). ‘The Selfie Assemblage'. International Journal of Communication, 9, 1629-1646.

Highfield, T. (2016). Social Media and Everyday Politics. London: Polity. https://www.researchgate.net/profile/Nithyaprakash_Venkatasamy3/publication/282571020_Fashion_trends_and_t heir_impact_on_the_society/links/5612398d08ae4833751bd97c.pdf

Ibrahim, Y. (2015). 'Self-representation and the disaster event: self-imaging, morality and Immortality'. Journal of Media Practice, 16(3), 211-227. http://dx.doi.org/10.1080/14682753.2015.1116755

IDC, (2015). 'Smartphone OS Market Share Worldwide Quarterly Mobile Phone Tracker'. Available at http://www.idc.com/prodserv/ smartphone-os-market-share.jsp

Johnson \& J. Wanna (ed.), Abbott's Gambit: The 2013 Australian Federal Election (pp.81-94).Canberra, Australia: ANU Press.

Koliska, M., \& Roberts, J. (2015). 'Selfies: Witnessing and Participatory Journalism with a Point of View'. International Journal of Communication, 9, 1672-1685.

Koukoumidis, E., Martonosi, M., \& Peh, L. S. (2012). 'IEEE Transactions on Mobile Computing', 11(5), 707 - 723. http://dx.doi.org/10.1109/TMC.2011.275

Kramp, L., Carpentier, N., \& Hepp, A. (2015). 'Introduction: Researching the transformation of societal self-understanding'. In Kramp, L. et al (ed.), Journalism, Representation and the Public Sphere (pp.7-17). Bremen: edition lumiere.

Kumar, S. (2012). 'The fatal snare of proximity: live television, new media and the witnessing of the Mumbai attacks'. South Asian History and Culture, 3(4), 532-548. http://dx.doi.org/10.1080/19472498.2012.720068

Leary, M. R. (2013). 'Scholarly reflections on the selfie'. Oxford University Press Blog. Retrieved from http://blog.oup.com/2013/11/scholarly-reflections-on-the-selfie-woty-2013

Lingwood, J. (ed.) (1986). Staging the self: Self-portrait photography 1840s-1980s. London,UK: National Portrait Gallery.

Lunden, I. (2015). '6.1B Smartphone Users Globally By 2020, Overtaking Basic Fixed Phone Subscriptions. Techcrunch'. (posted on June 2 2) Available at http://techcrunch.com/2015/06/02/6-1b-smartphone-users-globally-by-2020-overtaking-basic-fixed-phone-subscrip tions/

Maniou, T., \& Eteokleous-Grigoriou, N. (2014). 'Television Vs Web 2.0 in the New Media Age: The effects of Information upon university students'. Communication Studies, 16(1), 2-32.

Mendelson, A., \& Papacharissi, Z. (2011). 'Look at us: Collective narcissism in college student Facebook galleries'. In Z. Papacharissi (ed.), A networked self: Identity,community and culture on social network sites (pp.251-273). New York, NY: Routledge.

O’Donnell, P., McKnight, D., \& Este, J.(2012). Journalism at the Speed of Bytes: Australian Newspapers in the 21st Century. Sydney: Media, Entertainment and Arts Alliance.

Oie, K. V. (2015). 'News Narratives in locative journalism - rethinking news for the mobile Phone'. Journal of Media Practice, 16(3), 245-262. http://dx.doi.org/10.1080/14682753.2015.1116763

Omar, Y.(2015). 'Selfie Journalism: When the smartphone meets storytelling + sharing'. RJR. Retrieved in April 2015 at http://www.rjr.ru.ac.za/rjrpdf/rjr_no35/selfie\%20journalism.pdf

Peters, J. D. (2001). 'Witnessing'. Media, Culture and Society, 23(6), 707-723. http://dx.doi.org/10.1177/016344301023006002

Saravanan, D., \& Nithyaprakash, V. (2015). 'Fashion Trends and its Impact on Society'. Paper presented at the International Conference on Apparels and Fashion, Talminadu, India.Retrieved 30 April 2016 at

Senft, T., \& Baum, N. (2015). 'What does the Selfie say? Investigating a Global Phenomenon'. International Journal of Communication, 9, 1588 - 1606.

Spence, J. (1986). Putting myself in the picture. London, UK: Camden Press. 
Storella, A. (2015). 'It's Selfie Evident: Spectrum Alienability and Copyrighted content in Social media'. Boston University Law Review, 94, 2046 - 2086.

Tifentale, A., \& Manovich, L. (2015). 'Selfiecity: Exploring Photography and Self-Fashiong in Social Media'. In Berry, D., \& Dieter, M. (ed.), Postdigital Aesthetics: Art, Computation and Design (pp.109-122). London: Macmillan. http://dx.doi.org/10.1057/9781137437204.0013

Veglis, A. (2012). 'Journalism and Cross Media Publishing: The case of Greece'. In Siapera, E. \& A. Veglis (ed.). The Wiley-Blackwell Handbook of Online Journalism (pp.209-230), UK: Blackwell Publishing. http://dx.doi.org/10.1002/9781118313978.ch12

Watkins, J., Hjorth, L., \& Koskinen, I. (2012). 'Wising Up: Revising Mobile Media in an age of smartphones'. Continuum: Journal of Media \& Cultural Studies, 26(5), 665-668. http://dx.doi.org/10.1080/10304312.2012.706456

Wearden, S., \& Fidler, R. (2001). 'Crain's Cleveland Business: Evaluating an e-Newspaper Concept for Tablet PCs'. Future of Print Media Journal, Spring. Available at http://www.futureprint.kent.edu/articles/wearden03.htm

This work is licensed under a Creative Commons Attribution 3.0 License. 